\title{
THE DENOMINATOR NEGLECT IN DECISION-MAKING
}

\author{
Eva BALLOVÁ MIKUŠKOVÁ \\ Institute of Expreimental Psychology, Slovak Academy of Sciences \\ Dúbravská cesta 9, 84104 Bratislava, Slovak Republic \\ E-mail: expsbal@savba.sk
}

\begin{abstract}
People often pay too much attention to numerators and inadequate attention to denominators, this phenomenon is called denominator neglect. The aim of the study was mapping of frequency of denominator neglect, comparison of results with results of other studies and examination of possible moderators of denominator neglect. In two studies a total of 533 participants complete the Jellybean task, Vienna Matrix Test, Master Rationality Motive Scale, Cognitive Reflection Test, and Rational-Experiential Inventory. Results show that 1) denominator neglect was strongest in case of $8 \%$ probability (regardless whether alternative probabilities were equal or unequal), 2) motivated participants made significantly less suboptimal choices than unmotivated participants, and 3 ) there was no effect of cognitive ability, motive for rational integration and experiential thinking disposition, but low cognitive reflection and rational thinking style predicted denominator neglect.
\end{abstract}

Key words: ratio-bias phenomenon, denominator neglect, decision-making

\section{Introduction}

If you want to buy a lottery ticket, would you choose from a pile in which one out of ten is a winner, or would you choose from a pile in which nine out of a hundred are winners? If you prefer to choose from the second pile, you probably pay more attention to the numerator than to the denominator. This phenomenon is not rare; it is called de-

\footnotetext{
Acknowledgment

The author wishes to thank Vladimíra Čavojová for her time and useful discussion, participants for their willingness to participate in this research and the anonymous reviewer for his/her valuable comments and suggestions to improve the study.

This work was supported by a grant of Ministry of Education VEGA no. 2/0064/13: "Decision making of experts: Using intuition for solving strategic tasks" awarded to V. Čavojová.
}

nominator neglect, or ratio-bias phenomenon (in the present study I use the term denominator neglect). Denominator neglect is focusing on relative frequencies of numerators (Reyna \& Brainerd, 2008), paying attention to numerators (number of times an event has happened) and inadequate attention to denominators (overall number of opportunities for an event to happen) (e.g., GarciaRetamero, Galesic, \& Gigerenzer, 2010; Okan, Garcia-Retamero, Cokely, \& Maldonado, 2011; Passerini, Macchi, \& Bagassi, 2012), for instance, whether nine winning lottery tickets is few or many depends on the overall number of lottery tickets.

According to Alonso and FernándezBerrocal (2003) one reason of denominator neglect is that people better understand whole numbers than ratios (people automatically code frequencies) and second reason is that people better understand low num-

DOI: $10.21909 /$ sp.2015.03.698 
bers than large numbers. Low numbers are more concrete than large numbers and, furthermore, people have a social circle of around 100-200 people, so understanding probabilities with larger denominator may be difficult (Garcia-Retamero \& Galesic, 2011). For example, in terms of the occurrence of side effects, people have problems imagining the incidence of 1-in-1000, 1-in-10000, etc. Understanding numerical information seems to be important because it can lead to accurate judgement and decision making, especially in medical treatment when people focus more on treated and non-treated people who die and they do not consider the overall number of patients. In another study, Alonso and Fernández-Berrocal (2003) found that people made irrational decisions; they chose options with less objective probability due to higher numerator than in the alternative option.

Pacini and Epstein (1999) examined some determinants of denominator neglect and they found that participants scoring low in rational thinking made more suboptimal responses in Jellybean tasks. In another study, Alonso and Fernández-Berrocal (2003) found that people who chose the suboptimal options had lower score in rationality measured by Need for Cognition Scale, and Toplak, West, and Stanovich (2013) found that cognitive reflection predicted resistance to denominator neglect.

In previous studies (Alonso \& FernándezBerrocal, 2003; Garcia-Retamero \& Galesic, 2011; Pacini \& Epstein, 1999; Toplak, West, $\&$ Stanovich, 2013) denominator neglect was described in terms of its frequencies and its predictors. In the present study, the main aim was to replicate the above-mentioned findings: a) to examine the degree of denominator neglect and $b$ ) to verify possible relations of denominator neglect with cognitive ability, motive for rational thinking integration, preference of cognitive style, and cognitive reflection. The present study enriched denominator neglect research by using the Jellybean task with equal versus unequal and small versus large probabilities, next, by using self-reported scales as well as performance task to measure cognitive abilities, and by motivation of participants for optimal (maximal) performance.

In Study 1 simple Jellybean task was used -3 tasks with unequal low probabilities and relationship between denominator neglect and cognitive ability and motive for rational integration was verified. In Study 2 more complex Jellybean task was used (14 items) and the effect of equality of probability (equal vs. unequal) and degree of probability (low vs. high) were examined, as well as relationships between denominator neglect and motive for rational integration and thinking dispositions. In contrast to Study 1, participants were incentivized by extra credits dependent on the accuracy of their choices in the Jellybean task.

\section{Study 1}

The aim of Study 1 was verification of the denominator neglect (measured by different unequal probabilities $-6 \%, 7 \%$, and $8 \%$ versus $10 \%$ ) on a sample of future teachers. My first hypothesis was that future teachers neglect the denominator to a similar extent as it was reported in other studies (optimal and suboptimal choices of different probabilities were compared). For example, Lefebvre, Vieider, and Villeval (2009) found that $47 \%$ of participants $(41 \%$ in research of Dale, Schwarz, Rudski, and Smith (2007)) selected the suboptimal choice, and Passerini 
et al. (2012) state that $61 \%$ of participants chose the urn with $9 \%$ probability and $40 \%$ of participants the urn with 7\% probability of winning, compared to the urn with $10 \%$ probability.

My second hypothesis was that suboptimal choices will be predicted by lower cognitive ability and/or lower motive for rational integration. Alonso and Fernández-Berrocal (2003) found an association between Need for Cognition Scale and denominator neglect, and Toplak et al. (2013) found that resistance to denominator neglect was predicted by higher cognitive ability and thinking dispositions.

\section{Methods}

\section{Participants}

The study sample consisted of 428 participants from the Slovak Republic $(86 \%$ women) who were full-time students of the Constantine the Philosopher University in Nitra (Faculty of Education). There were differences in gender composition $\left(\chi^{2}=227.41\right.$, $p=.000)$ compared to the hypothesized 5050 distribution. Age of participants ranged from 18 to $26(M=19.67 ; S D=1.11)$. Participants received extra credits for their participation.

\section{Procedure}

Participants were recruited from courses of General and Social psychology at the Faculty of Education to complete the denominator neglect measure, cognitive ability and motive for rational integration measures as well as some other measures not reported here. The cognitive abilities measure was administrated in a group as part of a lecture to 401 participants from the total sample. All measures were administered online via www.survio.com. Students received course credit for their participation regardless of the accuracy of their choices.

\section{Measures}

Denominator neglect (ratio-bias phenomenon): Jellybean task (JBT)

The text version of the Jellybean task as a game of chance (Kirkpatrick \& Epstein, 1992) was used. The three problems with unequal probabilities were modelled and in each problem participants had to choose between one of two combinations of red and white jellybeans: "small urn" with 10\% probability of pulling out a red jellybean (1 of 10) or "large urn" with lower probability of pulling out a red jellybean [in the first problem there was $6 \%$ (60 from 1000) probability, in the second $7 \%$ ( 7 from 100) probability, and in the third $8 \%$ (40 from 500) probability]. Subjects were instructed to choose the alternative in which they had a higher chance to pull out a red jellybean.

Participant's choices were assessed by two measures (like in the Denes-Raj's and Epstein's study from 1994): 1) unweighted score indicating the number of suboptimal choices (optimal choice was assigned a score of 0 , and a suboptimal choice was assigned a score of 1); and 2) weighted score indicating the degree of suboptimal choice (an optimal choice was assigned a score of 0 , a suboptimal choice of $8 \%$ probability a score of 1 , a suboptimal choice of $7 \%$ probability a score of 2 , and a suboptimal choice of $6 \%$ probability a score of 3 ). The unweighted score could range from 0 (all optimal choices) to 3 (all suboptimal choices), 
and weighted score could range from 0 (all optimal choices) to 6 (all suboptimal choices). In both cases higher values indicated higher subjection to denominator neglect.

Cognitive ability: Vienna Matrix Test (VMT)

VMT is based on the classical Raven's test of progressive matrices - two items are from Standard Progressive Matrices and 1 from Advanced Progressive Matrices constructed by Raven. It consists of 24 items increasing in difficulty and is time-limited (25 minutes). Every task contains picture matrix $3 \times 3$ with the missing picture in the third row. The task of the participant is to fill in correctly one of the eight possibilities. The VMT shows high correlations with Intelligence Structure Test and the authors conclude that it reflects reliably a general cognitive factor. The test is supposed to be culture-fair as it is based on a figural content. We used the Czech adaptation by Klose, Černochová, and Král (2002).

Motive for rational integration: Master Rationality Motive Scale

Master Rationality Motive Scale (MRMS, Stanovich, 2011) measures the construct of rational motivation (felt need for rational in- tegration). It combines questions from few other scales, mostly measuring cognitive styles or personality. MRMS consists of 15 questions. Five questions are new (items 8 13), but all others are from different scales and inventories. I used a 6 point Likert scale ( 1 - completely disagree to 6 - completely agree). Scores could range from 15 (little motive for rational integration) to 90 (high motive for rational integration). Internal consistency of MRMS was examined by Hanák, Čavojová, and Ballová Mikušková (2014) and was quite low (Cronbach's alpha $=0.638)$.

\section{Results}

\section{Descriptive Statistics}

Descriptive statistics of the measures used (mean, standard deviation, median, 95\% CI) are presented in Table 1. Mean score of JBT unweighted score showed that 1.16 choices $(S D=1.17)$ from a total of 3 choices were suboptimal. Mean score from JBT weighted score was 2.29 points $(S D=2.37)$.

\section{Subjection to the Denominator Neglect}

Comparison of optimal and suboptimal choices of different probabilities shows that participants manifested the denominator ne-

Table 1 Descriptive statistics

\begin{tabular}{lcrrccc}
\hline & & & & & \multicolumn{2}{c}{$95 \% \mathrm{CI}$} \\
& $N$ & $M$ & $S D$ & Median & Lower Bound & Upper Bound \\
\hline JBT sum & 428 & 1.16 & 1.17 & 1 & 1.04 & 1.27 \\
JBT index & 428 & 2.29 & 2.37 & 2 & 2.06 & 2.52 \\
VMT & 428 & 107.41 & 15.47 & 109 & 105.89 & 108.93 \\
MRMS & 428 & 57.40 & 8.28 & 58 & 56.58 & 58.21 \\
\hline
\end{tabular}


glect most in case of the $8 \%$ probability (40in-500). In the other two cases ( $6 \%$ and $7 \%$ probability) the denominator neglect was lower (Table 2). Distribution of the optimal as well as suboptimal choices was tested. Chi square analysis showed a significantly different distribution compared to the random distribution (for more details see Table 2). Our findings were similar to the findings of Dale et al. (2007), Lefebvre et al. (2009) and Passerini et al. (2012).

\section{Predictors of Suboptimal Choices}

The extent to which cognitive ability (VMT) and motive for rational integration (MRMS) predict the denominator neglect (weighted sum score of JBT) was tested by linear regression analysis and there was no effect of cognitive ability and motive for rational integration on denominator neglect. Second, participants low (no optimal choice in JBT, $n=83$ ) and high (all optimal choices in JBT, $n=180$ ) in optimal choices were compared in their cognitive ability (VMT) and motive for rational integration (MRMS). No differences were found (for more details see Table 3).

\section{Discussion}

The purpose of Study 1 was the verification of the denominator neglect on a sample of future teachers. First, a similar extent of a

Table 2 Optimal and suboptimal choices in JBT

\begin{tabular}{cccc}
\hline & optimal & suboptimal & chi-square \\
\hline 6\% probability & $62.4 \%$ & $37.6 \%$ & $26.252^{*}$ \\
$7 \%$ probability & $63.6 \%$ & $36.4 \%$ & $31.439^{*}$ \\
(Passerini et al., 2012) & $(60 \%)$ & $(40 \%)$ & \\
8\% probability & $59.8 \%$ & $40.2 \%$ & $16.486^{*}$ \\
9\% probability & - & - & \\
(Dale et al., 2007) & $(58 \%)$ & $(42 \%)$ & \\
(Lefebvre et al., 2009) & $(53 \%)$ & $(47 \%)$ & \\
(Passerini et al., 2012) & $(39 \%)$ & $(61 \%)$ & \\
\hline
\end{tabular}

$* \mathrm{p}<.000$

Table 3 Comparison of participants subjected and not subjected to the ratio-bias

\begin{tabular}{llrrrrrrrr}
\hline & & & & & & & \multicolumn{3}{c}{$95 \%$ CI } \\
& choices & $N$ & $M$ & $S D$ & $t$ & $p$ & $d f$ & Lower & Upper \\
\hline \multirow{2}{*}{ VMT } & optimal & 166 & 108.75 & 17.94 & & & & \\
& suboptimal & 79 & 104.53 & 13.99 & 1.838 & 0.067 & 243 & -0.301 & 8.732 \\
\multirow{2}{*}{ MRMS } & optimal & 180 & 57.22 & 8.16 & -1.027 & 0.305 & 261 & -3.340 & 1.051 \\
& suboptimal & 83 & 58.36 & 8.92 & & & & & \\
\hline
\end{tabular}


denominator neglect as in previous studies (e.g., Dale et al., 2007; Lefebvre, Vieider, \& Villeval, 2009; Passerini et al., 2012) was hypothesized. Descriptive analysis showed that denominator neglect was strongest in case of the $8 \%$ probability. Although only three Jellybean tasks (three choices) were used, the results were consistent with the findings from other studies (e.g., Dale et al., 2007; Lefebvre et al., 2009; Passerini et al., 2012).

The second hypothesis was that lower cognitive ability and/or lower motive for rational integration predict denominator neglect (suboptimal choices). In contrast to Alonso and Fernández-Berrocal (2003) and Toplak, West, and Stanovich (2013) no effect of cognitive ability or motive for rational integration on denominator neglect was found. One possible explanation is that Alonso and Fernández-Berrocal (2003) used equal probabilities, and in Study 1 I used unequal probabilities. Because in some research (e.g., Okan et al., 2011, GarciaRetamero \& Galesic, 2011) there are different results for equal and unequal probabilities, in Study 2 I examined both equal and unequal probabilities. Another assumption could be a weak participants' motivation to make the best choices - they received extra credits for their participation regardless of choice's accuracy. So, in Study 2 both, effect of equal versus unequal probabilities and effect of incentives for participants were examined.

\section{Study 2}

In Study 1 only three Jellybean tasks were used and participants were not incentivized for maximal performance. In Study 2, Jellybean tasks were extended - probabili- ties of $6 \%, 7 \%$, and $8 \%$ were used as indicators of denominator neglect. Besides low probabilities, $12 \%, 13 \%$ and $14 \%$ probabilities and two tasks with $10 \%$ equal probabilities were used to determine whether the observed suboptimal choices are the result of denominator neglect or simply innumeracy. The main aim of Study 2 was verification of denominator neglect when equal and unequal probabilities were used and also when low and high probabilities were used. Dale et al. (2007, p. 247) found that "...suboptimal choices are far more frequent when the small urn is the optimal choice than when the big urn is optimal".

Another modification in Study 2 was motivation to choose as many optimal choices as possible. Dale et al. (2007) examined the effect of incentives denominator neglect and they stated that incentives can help people learn to choose the option that is most likely to win. Lefebvre et al. (2009) pointed out that one of the reasons for observed denominator neglect was the absence of (relevant) incentives. They introduced incentives for participants and they observed reduced denominator neglect. Therefore, in the present Study 2 relevant incentive was introduced for all participants: credits received by students for participation depended on the number of optimal choices; the more optimal choices a student made the more extra credits he/she received and the maximum possible amount of credit affected their final evaluation of the overall course. This was considered as a highly relevant incentive for students to participate in the study seriously and to be motivated for optimal performance (in contrast with typical performance; Toplak, West, \& Stanovich, 2011).

The second assumption was that lower denominator neglect is positively associated 
with higher cognitive ability and thinking dispositions (Alonso \& Fernández-Berrocal, 2003; Toplak, West, \& Stanovich, 2013). The effect of motive for rational integration (measured by MRMS) on denominator neglect was examined, and in addition, one self-reported scale (Rational-experiential Inventory by Pacini \& Epstein, 1999) and one performance task (Cognitive Reflection Test by Frederick, 2005) were administrated to measure thinking dispositions.

\section{Methods}

\section{Participants}

Total of 105 full-time students at the Constantine the Philosopher University in Nitra (Faculty of Education) from the Slovak Republic ( $80 \%$ of women) participated in Study 2 . There were significantly more women than men $\left(\chi^{2}=37.80, p=.000\right)$ and the age of participants ranged from 19 to 49 $(M=22.10 ; S D=4.45)$.

\section{Procedure}

Participants were recruited in courses of Social psychology and Statistics at the Faculty of Education to complete the denominator neglect measure, motive for rational integration measures and thinking dispositions measures. All instruments were administered online via www.survio.com. To maximize per- formance of the participants, they were incentivized by extra credits dependent on the accuracy of their choices in JBT: the more accurate choices, the more extra credits they could receive (the minimum of half accurate choices was stipulated to obtain at least 1 extra credit, the maximum were 4 extra credits for 13-14 correct choices).

\section{Measures}

Denominator neglect (ratio-bias phenomenon): Jellybean task

As in Study 1, the text version of the Jellybean task (JBT) as a game of chance (Kirkpatrick \& Epstein, 1992) was used and a total of 14 problems were modelled: 8 problems with equal probabilities and 6 problems with unequal probabilities, where in each problem participants had to choose between one of two combinations of red and white jellybeans. Three of the problems with unequal probabilities were modelled as a choice between a "small" urn with $10 \%$ probability of pulling out a red jellybean (1 of 10 ) or a "large" urn (with $6 \%, 7 \%$ and $8 \%$ probability), and three of the problems with unequal probabilities were modelled as a choice between a "small" urn with $10 \%$ probability (1 of 10) or a "large" urn (with $12 \%, 13 \%$ and $14 \%$ probability); for review of task combinations see Table 4). Subjects were instructed to choose a combination in

Table 4 Review of Jellybean tasks combination

\begin{tabular}{lcc}
\hline & equal probabilities & unequal probabilities \\
\hline low probabilities & 3 tasks $(6 \%, 7 \%, 8 \%)$ & 3 tasks $(6 \%, 7 \%, 8 \%$ vs. $10 \%)$ \\
$10 \%$ probabilities & 2 tasks & -- \\
high probabilities & 3 tasks $(12 \%, 13 \%, 14 \%)$ & 3 tasks $(12 \%, 13 \%, 14 \%$ vs. $10 \%)$ \\
\hline
\end{tabular}


which they had a higher chance to pull out a red jellybean.

For equal and unequal probabilities, the unweighted score (number) of suboptimal choices was computed as the indicator of denominator neglect (optimal choice was assigned a score of 0 , and a suboptimal choice was assigned a score of 1 ). The sum score of the wrong choices in items with $12 \%$, $13 \%$ and $14 \%$ probabilities (against $10 \%$ ) in the large urn was computed as the control score of innumeracy.

Motive for rational integration: Master Rationality Motive Scale

Master Rationality Motive Scale (MRMS, Stanovich, 2011) was administrated to all participants (for descriptions see Study 1).

\section{Thinking dispositions}

Self-reported Rational-Experiential Inventory (REI) and Cognitive Reflection Test (CRT) were used to measure thinking dispositions.

The REI (Pacini \& Epstein, 1999) is based on Cognitive-Experiential Self-Theory (e.g., Epstein, 2003) and consists of two scales Need for Cognition (basis for Rationality scale) and Faith in Intuition (basis for Experientiality scale). Epstein developed several versions of the REI, but in the present study I used the shortened version of REI (20 items) modified for Slovak population by Ballová Mikušková, Čavojová, and Hanák (2015). REI measures two thinking styles and includes four dimensions: Rational engagement and Rational ability (together they form the Rational thinking style, 10 items), and Experiential engagement and Experiential ability (together they form the Experiential thinking style, 10 items). Items were evaluated on a 6-point Likert scale (1 meaning "totally disagree" to 6 "totally agree").

The seven-item version of CRT (Toplak et al., 2013) was used as the better predictor of cognitive ability and thinking dispositions (Toplak, West, \& Stanovich, 2013) than the three-item version of CRT (Frederick, 2005). CRT problems seem to be easy and trigger an automatic - intuitive response, which must be overridden by more deliberate Type 2 processes. And it requires a) cognitive reflection to realize that the intuitive answer is not correct and b) cognitive ability to compute the right answer. Sums of correct and intuitive answers were computed; the sums formed composite scores, where higher values in correct answers indicated more rational reasoning and higher values in intuitive answers indicated more intuitive reasoning.

\section{Results}

\section{Descriptive Statistics}

Descriptive statistics of the measures used (mean, standard deviation, median) are presented in Table 5. Mean of suboptimal choices sum score in the Jellybean task showed that 1.81 choices $(S D=1.97)$ from a total of 6 equal and 6 unequal probabilities were suboptimal. When controlling for innumeracy, there were no suboptimal choices in tasks with high unequal probability (absence of innumeracy) and only .49 $(S D=.81)$ suboptimal choices in 3 tasks with high equal probability.

In case of unequal probabilities the participants manifested the denominator neglect most when $8 \%$ probability (80-in-1000) was evaluated $(43.3 \%)$ and in case of equal probabilities when $13 \%$ probability (13-in-100, 65- 
Table 5 Descriptive statistics

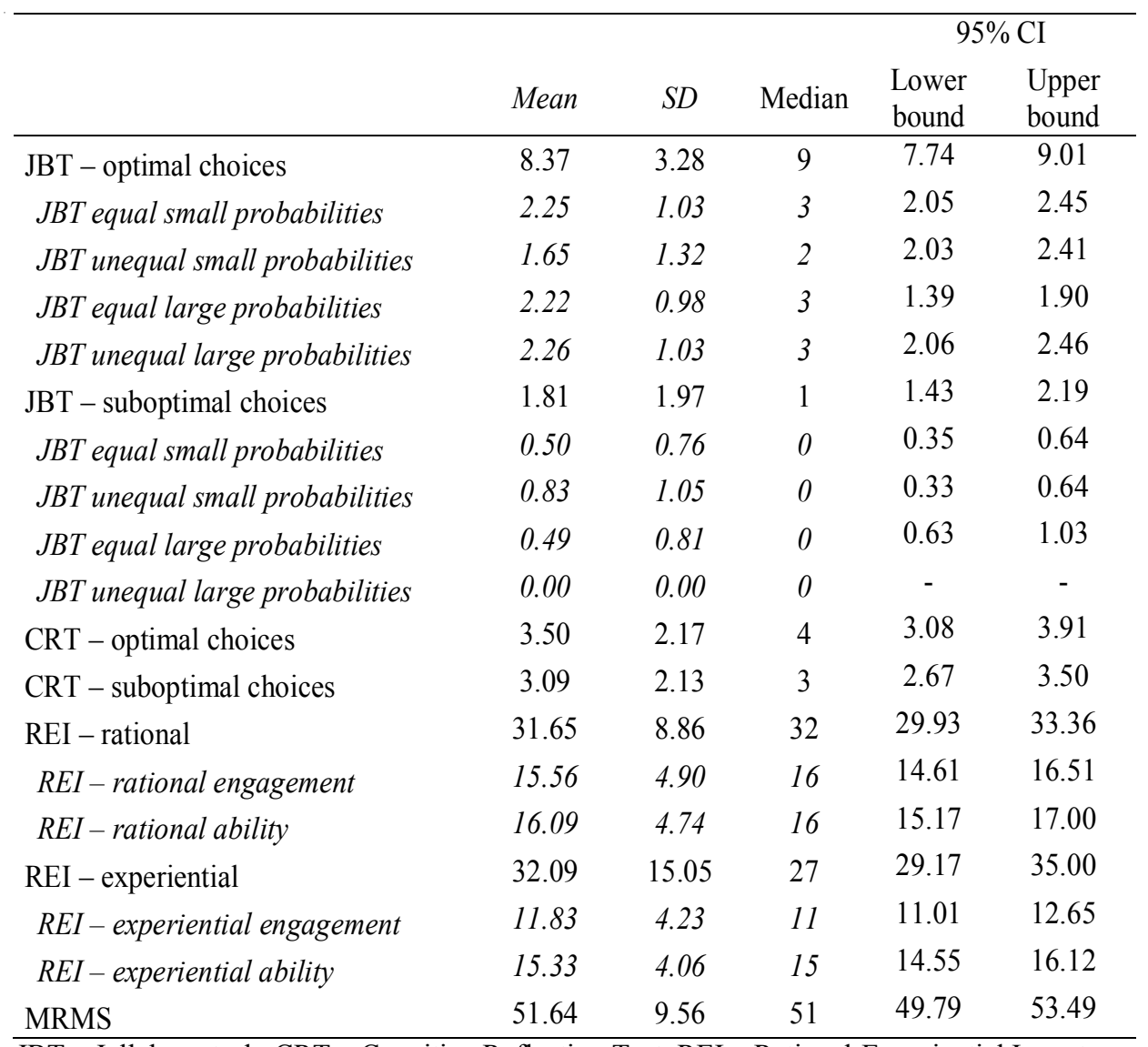

JBT - Jellybean task, CRT - Cognitive Reflection Test, REI - Rational-Experiential Inventory, MRMS - Master Rationality Motive Scale

in-500) was evaluated (62.2\%). The lowest denominator neglect was in $10 \%$ equal probabilities and 14\% unequal probability (for more details see Table 6).

\section{The Analysis of Variance}

The means and $95 \%$ confidence intervals for suboptimal choices in equal and unequal probabilities, and in low probabilities in the small urn and in high probabilities in large urn are presented in Table 5. The likelihoods of suboptimal choices (denominator neglect) as well as optimal choices (resistance to denominator neglect) in equal/unequal versus low/high probabilities were further analyzed with a repeated ANOVA measure with two within-participants factors of equality of probabilities (equal $x$ unequal) and degree of probability (low x high). 
Table 6 Optimal and suboptimal choices in equal and unequal items of JBT

\begin{tabular}{lcccc}
\hline & \multicolumn{2}{c}{ equal } & \multicolumn{2}{c}{ unequal } \\
& optimal & suboptimal & optimal & suboptimal \\
\hline 6\% probability & $74.3 \%$ & $17.1 \%$ & $60.0 \%$ & $26.7 \%$ \\
$7 \%$ probability & $75.2 \%$ & $13.3 \%$ & $59.0 \%$ & $22.9 \%$ \\
$8 \%$ probability & $75.2 \%$ & $19.0 \%$ & $45.7 \%$ & $33.3 \%$ \\
$10 \%$ probability & $89.5 \%$ & $6.7 \%$ & - & - \\
$10 \%$ probability & $87.6 \%$ & $7.6 \%$ & - & - \\
$12 \%$ probability & $76.2 \%$ & $17.1 \%$ & $69.5 \%$ & $12.4 \%$ \\
$13 \%$ probability & $64.8 \%$ & $20.0 \%$ & $72.4 \%$ & $17.1 \%$ \\
$14 \%$ probability & $81.0 \%$ & $11.4 \%$ & $83.8 \%$ & $6.7 \%$ \\
\hline
\end{tabular}

The analysis of variance of suboptimal choices revealed that the main effects, due to the equality of probabilities, was not significant $(F(1,104)=1.058, p=0.306$, partial $\left.\eta^{2}=0.010\right)$. On the other hand, the main effect of degree of probabilities was significant $(F(1,104)=39.898, p<0.001$, partial $\left.\eta^{2}=0.277\right) ; 27.7 \%$ of the variation in likelihood estimations can be accounted for by degree of probability (there were no suboptimal choices in high unequal probabilities; for more details and post-hoc tests see Table 7). Also, the interaction between equality and degree of probability was significant $\left(F(1,104)=52.490, p<0.001\right.$, partial $\left.\eta^{2}=0.335\right)$.

Post hoc comparisons using the t-test with

Table 7 Differences between suboptimal choices with equal/unequal and low/high probabilities

\begin{tabular}{lcccccc}
\hline $\begin{array}{l}\text { suboptimal } \\
\text { probability }\end{array}$ & Mean & $S D$ & $d f$ & $t$ & $p$ & $d$ \\
\hline $\begin{array}{l}\text { low } \\
\text { equal }\end{array}$ & .50 & .76 & 104 & 3.162 & .002 & .360 \\
$\begin{array}{l}\text { unequal } \\
\text { high }\end{array}$ & .83 & 1.05 & & & & \\
equal & .49 & .81 & 104 & 6.145 & .000 & .855 \\
unequal & .00 & .00 & & & & \\
equal & .50 & .76 & 104 & .139 & .889 & .013 \\
$\begin{array}{l}\text { low } \\
\text { high }\end{array}$ & .49 & .81 & & & & \\
unequal & & .00 & & & & \\
low & .83 & 1.05 & 104 & 8.077 & .000 & 1.091 \\
high & .00 & .00 & & & & \\
\hline
\end{tabular}


Bonferroni correction (after Bonferroni correction the statistical threshold was adjusted to .0125) indicated significant differences among the mean score of all types of probabilities (high, low, equal, unequal); the only exception was the absence of significant difference between the mean score in low and high equal probabilities (Table 7).

To control the effect of innumeracy, participants were divided into two groups: those with good numeracy skills (no suboptimal choices in control tasks with equal and unequal $12 \%-14 \%$ probability, $n=71$ ) and those with poorer numeracy skills (more than 1 suboptimal choice in control Jellybean tasks, $n=34$ ). Participants with good numeracy skills were significantly more resistant to denominator neglect $(M=.23, S D=.52 ; t=$ $6.095 ; p=.000 ; d=1.144)$ than those with poorer numeracy $(M=1.06, S D=.89)$, but only when choosing from alternatives with equal probabilities (in case of unequal probabilities, there were no differences between participants with good and poorer numeracy).

\section{Predictors of Denominator Neglect}

The effect of motive for rational integration (MRMS) and thinking dispositions (REI) on denominator neglect (suboptimal choices) in tasks with low probabilities (as the most relevant indicator of denominator neglect) was tested by linear regression analysis. There was no effect of motive for rational integration and REI-experiential thinking disposition on denominator neglect. On the other hand, two predictors of denominator neglect were identified: first, REI-R positively correlated with suboptimal choices in Jellybean task $(r=.418, p<.000)$ and a linear regression showed that REI-R could significantly predict denominator ne- glect, $F(1,103)=21.78, p=.000($ REI-R accounted for $17.5 \%$ of the explained variability in denominator neglect).

On the other hand, suboptimal answers in CRT positively correlated with suboptimal choices in Jellybean tasks $(r=.415 ; p<.000)$ and could statistically significantly predict denominator neglect, $F(1,103)=21.39, p=$ .000 (suboptimal answers in CRT accounted for $17.2 \%$ of the explained variability in denominator neglect). To summarize, the more participants assessed themselves as rational in the self-reported scale(REI), the more they manifested denominator neglect, but in case of performance task (CRT), the more participants performed suboptimally in CRT, the more they manifested denominator neglect.

\section{Discussion}

Jellybean tasks and procedure were modified in Study 2, 14 tasks with equal/unequal and low/high probabilities were used and participants were incentivized to optimal choices by extra credits. The main aim was the verification of denominator neglect when equal and unequal probabilities were used and also when low and high probabilities were used. Participants subjected to the denominator neglect most when $8 \%$ unequal probability (as in Study 1 and in other studies, e.g., Dale et al., 2007; Lefebvre et al., 2009; Passerini et al., 2012), and 13\% equal probability was evaluated. Study 2 was extended by control of numeracy through tasks with equal/unequal high probabilities (12\%-14\%). Participants with good numeracy skills were more resistant to denominator neglect than those with poorer numeracy when choosing from alternatives with equal probabilities, but not when choosing from alternatives with unequal probabilities. Further examination 
(for example in samples with different level of mathematical education) is necessary to verify whether numeracy can protect us from denominator neglect also in case of unequal probabilities. If yes, through good numeracy we can improve rational and critical thinking as well.

Next, the effect of equality and degree of probabilities was tested: the effect of probabilities equality was not significant, contrary to the effect of the probabilities' degree: participants chose no suboptimal choice in case of high unequal probability and they chose more suboptimal choices in case of low unequal probability. This finding is consistent with Dale et al. (2007) results - in their research suboptimal choices were more frequent when the low urn was the optimal choice (contrary to the case when big urn was optimal).

Finally, the effect of motive for rational integration, cognitive ability and thinking dispositions on denominator neglect was verified. There was no effect of motive for rational integration and experiential thinking disposition, but self-reported rational thinking style predicted denominator neglect (choosing suboptimal choices in Jellybean tasks): it seems that belief in one's own rationality does not guarantee that people will choose optimally. On the other hand, suboptimal performance in CRT could predict suboptimal choices in the Jellybean task - denominator neglect seems to be related to lack of cognitive reflection. The assumption that resistance to denominator neglect is positively associated with higher cognitive abilities was supported only when performance tasks (JTB, CRT) were taken into account, but not when self-reported cognitive preferences (REI, MRMS) were analyzed. The type of task (performance versus self-reported) could explain conflicting results in the present study: there is evidence (Ballová Mikušková, Čavojová, \& Hanák, 2015) that people are consistent in self-assessment (relations between preferences for cognitive style measured by various self-reported scales), but the performance often does not meet a self-image (lack of relations between self-reported preference for thinking style and cognitive performance).

\section{General Discussion}

Denominator neglect (ratio-bias phenomenon) was explored in two studies to replicate the finding that people prefer alternatives with less (objective) probability due to higher numerator than in the alternative option (Alonso \& Fernández-Berrocal, 2003), and that low rationality predicts weak resistance to denominator neglect (Alonso \& Fernández-Berrocal, 2003; Pacini \& Epstein, 1999) and cognitive reflection predicts resistance to denominator neglect (Toplak, West, \& Stanovich, 2013).

In both studies denominator neglect was strongest when $8 \%$ unequal probabilities were evaluated. The effect of degree of probability was supported: denominator neglect was higher in case of low probabilities. This finding can serve as a support for the DenesRaj and Epstein (1994) argument that the number of suboptimal responses decreases when alternatives are extreme. In other words, the closer to $10 \%$ the probability is (especially in case of low probabilities), the more suboptimal choices people make. And, as the analysis of variance showed, it does not matter whether alternative probabilities are equal or unequal.

Next, the effect of cognitive ability, motive for rational integration and cognitive reflec- 
tion was examined. There was no effect of cognitive ability or motive for rational integration on denominator neglect. Self-reported preference of rational thinking style predicted denominator neglect, but this effect can be explained by self-reported type of scale. Low cognitive reflection can be considered a predictor of denominator neglect. To summarize, it seems that it is not the belief in one's own rationality, but cognitive reflection that determines accurate decisions.

Research of denominator neglect is important for two reasons. First, denominator neglect is one of the cognitive error indicators, it is one of the measurement paradigms of miserly information processing included in most of the dual-process theories (for more details see Stanovich, 2011): dual-process theories are built on importance of the override function of the Type 2 processing to replace early responses of Type 1 processing by better responses. Stanovich (2011) attributed this ability to the higher-level cognitive function, reflective mind that initiates this override. Furthermore, there are various types of errors arising from individual differences in preferring the use of these processes (Stanovich, 2011); one of them is denominator neglect.

Second and more important in terms of reallife consequences, understanding numerical information is important because it can lead to accurate judgement and decision making: avoiding denominator neglect is useful in situations when we need to estimate the risk, most often in medical treatment (GarciaRetamero et al., 2010) state that understanding numerical information, such as ratio concepts, make effective decisions about treatment), and also when evaluating chances of winning, or chances for employment. All examples are situations in which we are per- sonally involved; we have motivation to make the most accurate decision. But, can motivation facilitate accuracy of choices? Comparison of suboptimal choices in Study 1 (participants were incentivized for typical performance - no instruction to maximize performance; Toplak, West, \& Stanovich, 2011) and in Study 2 (participants were incentivized for maximal performance) showed that the answer is yes: participants incentivized by extra course credits to make as accurate choices as possible (Study 2) made significantly fewer suboptimal choices than those not incentivized.

The ability to override denominator neglect is important, therefore, some authors (e.g., Garcia-Retamero et al., 2010; Okan, Garcia-Retamero, Cokely, \& Maldonado, 2011; Stone et al., 2003) present recommendations for its improving: using visual display such as bar graph that include relations involving numerators and denominators, providing icon arrays that help to improve mathematical competence - to make more accurate assessments of risk reduction by drawing attention both to numerator and denominator. Although it appears that motivation can improve optimal choices, I have one more general recommendation: the inclusion of courses of critical thinking to universities, which could help improve mathematical competence as a part of rational thinking.

Received October 5, 2014

\section{References}

Alonso, D., \& Fernández-Berrocal, P. (2003). Irrational decisions: Attending to numbers rather than ratios. Personality and Individual Differences, 35, 1537-1547.

Ballová Mikušková, E., Hanák, R., \& Čavojová, V. (2015). Appropriateness of two inventories mea- 
suring intuition (The PID and the REI) for Slovak population. Studia Psychologica, 57(1), 63 82 .

Dale, D., Schwarz, A., Rudski, J., \& Smith, E. (2007). Innumeracy and incentives: A ratio bias experiment. Judgment and Decision Making, 2(4), 243250 .

Denes-Raj, V., \& Epstein, S. (1994). Conflict between intuitive and rational processing: When people behave against their better judgment. Journal of Personality and Social Psychology, 66(5), 819-829.

Epstein, S. (2003). Cognitive-experiential selftheory of personality. In T. Millon \& M. J. Lerner (Eds.), Handbook of psychology: Personality and social psychology, Vol. 5 (pp. 159-184). John Wiley \& Sons

Frederick, S. (2005). Cognitive reflection and decision making. Journal of Economic Perspectives, 19(4), 25-42.

Garcia-Retamero, R., \& Galesic, M. (2011). Using plausible group sizes to communicate information about medical risks. Patient Education and Counseling, 84(2), 245-250.

Garcia-Retamero, R., Galesic, M., \& Gigerenzer, G. (2010). Do icon arrays help reduce denominator neglect? Medical Decision Making: An International Journal of the Society for Medical Decision Making, 30(6), 672-684.

Hanák, R., Čavojová, V., \& Ballová Mikušková, E. (2014). Educating rationality: Assessing master rationality motive in future teachers. In INTED2014 Proceedings, 6458-6463.

Kirkpatrick, L. A., Epstein, S. (1992). Cognitiveexperiential self-theory and subjective probability: Further evidence for two conceptual systems. Journal of Personality and Social Psychology, 63(4), 534-544.

Klose, J., Černochová, D., \& Král, P. (2002). Videňský maticový test. Testcentrum.
Lefebvre, M., Vieider, F., \& Villeval, M. (2009). The ratio bias phenomenon: Fact or artifact? Centre National de la Recherche Scientifiqua.

Okan, Y., Garcia-Retamero, R., Cokely, E. T., \& Maldonado, A. (2012). Individual differences in graph literacy: Overcoming denominator neglect in risk comprehension. Journal of Behavioral Decision Making, 25(4), 390-401, doi: 10.1002/ bdm. 751

Pacini, R., \& Epstein, S. (1999). The relation of rational and experiential information processing styles to personality, basic beliefs, and the ratiobias phenomenon. Journal of Personality and Social Psychology, 76(6), 972-987.

Passerini, G., Macchi, L., \& Bagassi, M. (2012). A methodological approach to ratio bias. Judgement and Decision Making, 7(5), 602-617.

Reyna, V. F., \& Brainerd, C. J. (2008). Numeracy, ratio bias, and denominator neglect in judgments of risk and probability. Learning and Individual Differences, 18, 89-107.

Stanovich, K. E. (2011). Rationality and the reflective mind. New York: Oxford University Press.

Stone, E. R., Sieck, W. R., Bull, B. E., Yates, J. F., Parks, S. C., \& Rush, C. J. (2003). Foreground:background salience: Explaining the effects of graphical displays on risk avoidance. Organizational Behavior and Human Decision Processes, 90(1), 19-36.

Toplak, M. E., West, R. F., \& Stanovich, K. E. (2011). The Cognitive Reflection Test as a predictor of performance on heuristics-and-biases tasks. Memory \& Cognition, 39(7), 1275-89. doi:10.3758/s13421-011-0104-1

Toplak, M. E., West, R. F., \& Stanovich, K. E. (2013). Assessing miserly information processing: An expansion of the Cognitive Reflection Test. Thinking \& Reasoning, 20(2), 147-168.

\section{ZANEDBÁVANIE MENOVATELAA PRI ROZHODOVANÍ}

$$
\text { E. B a } 11 \text { ová M i k u š k ová }
$$

Súhrn: Zanedbávanie menovatel'a je fenomén, kedy pri posudzovaní numerických pomerov l'udia venujú príliš vel'a pozornosti čitatel'ovi a príliš málo pozornosti menovatel'ovi. Ciel'om štúdie bolo replikovat' zistenia, že a) l'udia preferujú alternatívy s objektívne menšou pravdepodobnost'ou vd'aka vyššiemu čitatel'ovi ako iné alternatívy, že b) nižšia racionalita predikuje slabšiu rezistenciu voči zanedbávaniu menovatel’a, a že c) kognitívna reflexia predikuje rezistenciu voči zanedbávaniu menovatel'a. Celkovo 533 participantov v dvoch štúdiách vypíńalo úlohu s fazul'kami (Jellybean 
task), Viedenský matricový test, Škálu motivácie k racionalite, Test kognitívnej reflexie a Racionálno-experienciálny inventár. Z výsledkov vyplýva, že 1) zanedbávanie menovatel'a bolo najsilnejšie v prípade $8 \%$ pravdepodobnosti alternatív (bez ohladu na to, či boli pravdepodobnosti alternatív rovnocenné alebo nie), 2) motivovaní participanti vykazovali vyššiu rezistenciu voči zanedbávaniu menovatel'a ako nemotivovaní participanti, a 3) efekt kognitívnych schopností, motivácie $\mathrm{k}$ racionalite a dispozície $\mathrm{k}$ experienciálnemu mysleniu nebol overený, na druhej strane nižšia kognitívna reflexia a vyššia preferencia racionálneho myslenia predikovala zanedbávanie menovatel'a. 